\title{
Bio-Banding in Sport
}

\section{Sporda Biyo-Gruplama}

\author{
Mustafa Söğüt \\ Faculty of Sport Sciences, Kırıkkale University, Kırıkkale, Turkey
}

M. Söğüt iD

0000-0003-1826-8235

Geliş Tarihi / Date Received: 17.09.2018

Kabul Tarihi / Date Accepted: 16.10.2018

Yayın Tarihi /Published Online 28.12.2018

Yazışma Adresi /

Corresponding Author:

Mustafa Söğüt

Kırıkkale Üniversitesi, Spor

Bilimleri Fakültesi, Kırıkkale,

Türkiye

E-mail: msogut@kku.edu.tr

(C)2019 Türkiye Spor Hekimleri Derneği. Tüm hakları saklıdır.

\begin{abstract}
Children born in the same calendar year may vary in their growth and maturational status. These possible discrepancies can cause disadvantages especially for the young athletes who physically mature late and lead many talented ones to withdraw from sport at an early age. Scientists dealing with these issues, in collaboration with practitioners, introduce a new approach. This approach is called "bio-banding". Bio-banding is the process of grouping young athletes according to their attributes related with growth and biological maturation rather than their chronological age. The purpose of this study is to improve the awareness of Turkish scientists, coaches, administrators, and other stakeholders about bio-banding in sport by forming a conceptual framework regarding its methods, applications, and potential benefits.
\end{abstract}

Keywords: Biological maturation, growth, sport

Öz

Aynı takvim yılı içerisinde doğan çocukların büyüme ve olgunlaşma düzeyleri önemli ölçüde değişkenlik gösterebilmektedir. Olası bu farklılıklar özellikle olgunlaşma düzeyi düşük olan genç sporcular için bir dezavantaj oluşturmakta ve birçok yetenekli sporcunun erken yaşlarda spordan kopmasına sebep olmaktadır. Konuya iişkin araştırmalar yürüten bilim insanları, uygulamacılar ile iş birliğine girerek, karşılaşılan durumun önüne geçilmesi amacı ile yeni bir yaklaşım geliştirmişlerdir. Bu yeni yaklaşım "Biyo-gruplama" olarak tanımlanmıştır. Biyo-gruplama, genç sporcularda kronolojik yaş yerine büyüme ve biyolojik olgunlaşma özellikleri temel alınarak yapılan sınıflama yöntemidir. Bu çalışmada, sporda biyo-gruplama yönteminde kullanılan temel yöntemler ve uygulamalar ile birlikte potansiyel faydalarına ilişkin bir çerçeve çizilerek ülkemiz bilim insanları, antrenörleri, spor yöneticileri ve diğer paydaşların konu hakkındaki farkındalıklarının geliştirilmesi amaçlanmıştır.

Anahtar sözcükler: Biyolojik olgunlaşma, büyüme, spor

Available at: http://journalofsportsmedicine.org and http://dx.doi.org/10.5152/tjsm.2019.126

Cite this article as: Sogut M. Bio-banding in sport. Turk $J$ Sports Med. 2019;54(2):143-7.

\section{Gíriş}

Genç sporcular genellikle takvim yașları göz önünde bulundurularak antrenman ve müsabaka gruplarına ayrılırlar (1). Bu yöntem oldukça basit ve kullanıșlı olmasına rağmen, olası büyüme ve biyolojik olgunlașma düzey farklılıklarını göz ardı etmektedir. Önceki bazı araștırmalar bu farklılıkların önemli boyutlara ulașabildiğini göstermiștir $(2,3)$. Örneğin Johnson (2), aynı hafta içerisinde doğmuş yaşıt iki genç futbolcunun kemik yaşları arasında yaklaşık altı yıllık bir fark saptamıștır. Benzer bir şekilde, Malina 
ve ark. (3) aynı yaș kategorisinde (U12) mücadele eden iki futbolcu arasındaki boy uzunluğu açıklığını $39 \mathrm{~cm}$ olarak bulmuştur. Diğer taraftan, kategoriler olușturulurken biyolojik olgunluğa gereken önemin verilmemesi, genç sporcuların yetilerinin objektif bir şekilde değerlendirilememe riskine neden olabilmektedir (4).

Biyolojik olgunluk düzeyinin antropometrik ve fonksiyonel özellikler üzerindeki değişimlerini inceleyen geçmiş bazı araştırmalar futbol $(5,6)$, basketbol $(7,8)$, tenis $(9,10)$ ve hentbol $(11)$ oyunlarında erken olgunlaşan sporcuların aynı kronolojik yaştaki geç veya normal olgunlaşma düzeylerindeki akranlarına oranla daha yüksek değerler sergilediklerini not etmiştir. Malina ve ark.na (5) göre özellikle adolesan dönemde, aynı kronolojik yaştaki erken ve geç olgunlaşma düzeylerindeki erkek futbol oyuncuları arasında kuvvet ve sürat ile ilgili parametrelerde önemli farklılıklar gözlenmektedir. Benzer bir çalışmada Myburgh ve ark. (9) biyolojik olarak erken olgunlaşmanın genç erkek tenis oyuncularına el kavrama kuvveti, sürat, dikey sıçrama ve üst vücut kuvveti; kız oyunculara ise el kavrama kuvveti ve çeviklik performanslarında avantaj sağladığını belirtmiştir.

Baker ve Logan (12)'a göre, biyolojik yaşları önde olan sporcular başarı ve ödülü daha fazla deneyimledikleri için psikolojik üstünlük sağlarlar ve spora katılımları daha kalıcı olur. Öte yandan, morfolojik yapıları çok fazla değişkenlik gösteren çocukların müsabakalarda karşılaştıkları fiziksel mücadele yaralanma riskini daha fazla arttırabilir.

Genç sporcuların eşit şartlarda ve en uygun bir şekilde gelişim sağlayabilecekleri antrenman ve müsabaka ortamının oluşturulmasının önemine değinen bilim insanları; uygulamacılar ile iş birliği içine girerek, yeni bir bakış açısı geliştirdiler. $\mathrm{Bu}$ yaklaşım "Biyo-gruplama" olarak tanımlanmıştır. Biyo-gruplama, genç sporcularda kronolojik yaş yerine büyüme ve biyolojik olgunlaşma özellikleri temel alınarak yapılan gruplama yöntemidir (1).

\section{Biyolojik olgunlaşma düzeyi belirleme yöntemleri}

Biyolojik olgunlaşmanın belirlenmesi genç sporcuda performans gelişiminin gözlenmesinde en önemli araçlardandır (2). Biyolojik olgunlaşma, biyolojik olgunluk düzeyine doğru ilerlemeyi ifade eder (13). Biyo-gruplama genç sporcuların öncelikle hangi olgunlaşma düzeyinde olduklarının saptanması ve bu doğrultuda antrenman veya müsabaka gruplarına ayrılmalarını temel alır. $\mathrm{Bu}$ nedenle, biyolojik olgunlaşma düzeyinin doğru bir şekilde değerlendirilmesi yöntemin ideal olarak uygulanmasında büyük önem taşır. Biyolojik olgunlaşmanın belirlenmesinde iskelet yaşı, cinsel olgunlaşma ve somatik yöntemler sıklıkla kullanılır $(14,15)$. Araştırma grubunun özellikleri, teknolojik olanaklar ve araştırmanın amacl, yöntem seçiminde göz önünde bulundurulması gereken en önemli etkenlerdir.

İskelet yaşının saptanması el-el bileği röntgen görüntüsü alınarak kemikleşmenin çeşitli atlaslar yardımı ile analiz edilmesini içerir $(15,16)$. Her ne kadar olgunlașmanın belirlenmesinde en geçerli yöntem olarak düşünülse de; maliyetli oluşu, özel cihaz gerektirmesi ve düşük de olsa katılımcıları radyasyona maruz bırakması uygulamada tercih edilmesini sınırlamaktadır $(13,17,18)$. Diğer bir yöntem olan cinsel olgunlaşma düzeyinin saptanması ise ikincil cinsel özelliklerin (pubik kıllanma, gögüs gelişimi vb.) doğrudan gözlemi üzerine dayanmakta ve bu durum özellikle klinik olmayan ortamlarda çeşitli etik zorluklar barındırır $(13,14,16,18-21)$. $\mathrm{Bu}$ yöntem bazı sosyo-kültürel gruplarda hem çocuklar hem de ebeveynler tarafından rahatsız edici bulunmakta ve özel hayatın gizliliğine müdahale ile ilişkilendirilmektedir $(13,16,21)$.

$\mathrm{Bu}$ problemin önüne geçilmesi adına cinsel özelliklerin gelişiminin bireysel değerlendirmesini içeren anketler geliştirilmiştir $(13,21,22)$. Fakat anket ile yapılan ölçümlerde de çocukların biyolojik olgunluklarını olduklarından fazla veya daha az değerlendirdikleri araștırmalarda not edilmiştir $(21,23)$. Cumming ve ark. (1) bu iki yöntemin genç sporcunun olgunlaşma düzeyinin belirlenmesinde pratik olmadığını, bunların 
yerine noninvazif, antropometrik özelliklerin ölçümüne dayanan ve uygulaması kolay olan somatik yöntemlerin alanda çok sıklıkla kullanıldığını belirtmişlerdir. $\mathrm{Bu}$ yöntemler zirve boy hızı yaşının ve tahmini yetişkinlik boy uzunluğunun değerlendirilmesidir.

\section{Zirve Boy Hızı Yaşının Belirlenmesi}

$\mathrm{Bu}$ yöntem ergenlik dönemindeki büyüme atağı sırasında boy uzunluğundaki maksimum artış yaşının tahmini olarak hesaplanmasını içerir (15). Mirwald ve ark. (18) tarafından geliştirilen formüller (bkz. erkekler için formül 1, kızlar için formül 2) spor bilimlerine ilişkin çalışmalarda oldukça sık kullanılmaktadır. Formüller yardımı ile tahmini zirve boy hızı zamanına kalan süre hesaplanır. Hesaplamada cinsiyet, doğum tarihi,

ölçüm tarihi, boy uzunluğu, oturma yüksekliği, bacak uzunluğu ve vücut ağırlığı değişkenlerinin kaydedilmesi gerekir. Daha sonra kronolojik yaş ile tahmini zirve boy hızı zamanına kalan süre arasındaki fark saptanarak zirve boy hızı yaşı bulunur. Son olarak ortalama ve standart sapma değerleri hesaplanarak araştırma grubu biyolojik olgunlașma durumlarına göre kategorilere $(<-1$ geç, -1 ile 1 arası zamanında ve $>1$ erken şeklinde) ayrllırlar (24).

Formül 1: -9.236 + 0.0002708 (bacak uzunluğu x oturma yüksekliği) - 0.001663 (yaş x bacak uzunluğu) + 0.007216 (yaş x oturma yüksekliği) + 0.02292 (vücut ağırlığı/boy uzunluğu x 100)

Formül 2: -9.376 + 0.0001882 (bacak uzunluğu x oturma yüksekliği) + 0.002200 (yaş x bacak uzunluğu) + 0.005841 (yaş x oturma yüksekliği) - 0.002658 (yaş x vücut ağırlığı) + 0.07693 (vücut ağırlığı/boy uzunluğu x 100)

\section{Tahmini Yetişkinlik Boy Uzunluğunun Belirlenmesi}

Biyo-gruplamada genç sporcuların biyolojik olgunlaşma düzeylerinin belirlenmesinde sı başvurulan bu somatik yöntemde, öncelikle tahmini yetişkinlik boy uzunluğunun Khamis ve Roche (25) tarafından geliştirilen regresyon denklemi (Tahmini yetişkinlik boy uzunluğu $=\beta_{0}$ $+\beta_{1}$ [boy uzunluğu (inç)] $+\beta_{2}$ [vücut ağırlığı (lb)] $+\beta_{3}$ [ebeveynlerin ortalama boy uzunlukları (inç)]) ile hesaplanması gerekmektedir. Hesaplamada kız ve erkek çocukları için ayrı ayrı hazırlanan, boy uzunluğu, vücut ağırlığı ve biyolojik ebeveynlerin ortalama boy uzunlukları regresyon katsayılarını içeren tablolar (bkz. Khamis ve Roche, s. 505) kullanılmaktadır. Örneğin kronolojik yaşı 9, boy uzunluğu $135 \mathrm{~cm}$, vücut ağırlığı $35 \mathrm{~kg}$ ve ebeveyn ortalama boy uzunluğu $175 \mathrm{~cm}$ olan bir erkek sporcunun tahmini yetişkinlik boy uzunluğu $187 \mathrm{~cm}$ olarak bulunur. Bir sonraki adımda, tahmini yetişkinlik boy uzunluğu temel alınarak ölçüm sırasındaki boy uzunluğunun yüzdesel karşılığı hesaplanır (örnekteki sporcu için bu değer \%72'dir). Son olarak, elde edilen yüzdelik değerlere göre genç sporcular farkl biyolojik olgunluk kategorilerine $(<\% 85$ ergenlik öncesi, $\geq \% 85$ $<\% 90$ erken ergenlik, $\geq \% 90 \quad-<\% 95$ ergenlik dönemi ve $\geq \% 95$ geç ergenlik) ayrılabilirler (1).

\section{Biyo-gruplama uygulamaları}

Eşit yarışma ortamı sağlanması ve potansiyel sakatlık risklerinin engellenmesi amacı ile güreş, boks, judo ve tekvando gibi sıklet sporlarında genç sporcular yaş ve vücut ağırlıklarına göre uzun süredir kategorilere ayrılmaktadır $(26,27)$. Buna karşıllk, biyo-gruplama yönteminde tek bir antropometrik özellik yerine birçok değişken kullanılmakta ve bu sayede farklı kronolojik yaşlardaki sporcular aynı antrenman ve müsabaka gruplarında yer alabilmektedirler.

Biyo-gruplama yönteminin uygulandığı ve sonuçlarının rapor edildiği ilk bilimsel çalışma Cumming ve çalışma arkadaşları (28) tarafından gerçekleştirilmiştir. Araştırmada 2016 yılında Premier Lig tarafından organize edilen ve biyogruplama yönteminin uygulandığı bir turnuvada genç futbolcuların karşılaşmalardaki deneyim ve algıları değerlendirilmiştir. Çalışmaya tahmini yetişkinlik boy uzunluğu yüzdesi 85-90 arasında 
olan ve Premier Ligdeki dört takımın (Reading, Southampton, Stoke City ve Norwich City) futbol akademilerinde yer alan 11-14 yaşları arasındaki 66 futbolcu katılmıştır. Araştırma grubunun biyolojik olgunlaşma düzeyleri Khamis ve Roche (25) metodu ile hesaplanmış ve erken ve geç olgunluk düzeylerindeki sporcular birbirlerinden ayrı gruplandırılmıștır. Sekizi erken ve sekizi geç olgunlaşma düzeylerindeki toplam 16 oyuncu odak grup olarak seçilmiş ve oynadıkları maçlardaki deneyimlerini fiziksel, teknik/taktik ve psikososyal başlıklar altında açıklamaları istenmiştir.

Araştırma sonucunda tüm oyuncuların kronolojik yaş yerine biyolojik olgunluk düzeyine göre düzenlenen müsabakaların daha adil bir yarışma ortamı sağladığını, biyo-gruplama yöntemini pozitif karşıladıklarını ve Premier Ligin mevcut programına entegre edilmesini önerdikleri not edilmiştir. Bununla birlikte, erken olgunlaşma düzeyindeki oyuncular biyo-gruplama ile oynanan maçları fiziksel açıdan daha zorlayıcı bulduklarını ve bu sayede fiziksel özellikleri yerine teknik ve taktik özelliklerini daha fazla ön plana çıkarabildiklerini not etmişlerdir. Geç olgunlaşan oyuncular ise yöntemi fiziksel olarak daha az zorlayıcı bulduklarını ve hem teknik hem de taktik özelliklerini daha fazla sergileyebildikleri için çok memnun kaldıklarını dile getirmişlerdir. Sonuç olarak, biyo-gruplama yönteminin genç futbolcuların bütünsel gelişimlerine pozitif katkı sağlayabileceği vurgulanmıştır.

\section{Biyo-gruplamanın potansiyel yararları}

Genç sporcuların biyolojik olgunluk düzeylerine göre antrenman ve müsabaka gruplarına ayrılmaları yalnızca son birkaç yıl içerisinde ve bazı ülkelerdeki futbol federasyonları (İngiltere ve $A B D$ ) tarafından denenmeye başlanmıştır. $\mathrm{Bu}$ nedenle, literatür yöntemin somut yararlarını ortaya koymak için yeterli bilimsel veri sunmamaktadır. Biyo-gruplamanın olası etkilerini gözlemleyebilmek için boylamsal çalışmalara başvurmak gerekmektedir.

Cumming ve ark. (1) biyo-gruplamanın genç oyuncular için sağlayabileceği potansiyel yararları; olası yaralanmaların önlenebilmesi, eşit yarışma ortamı sağlanabilmesi, daha verimli antrenman ortamı oluşturularak performans gelişimi sağlanabilmesi, yetenek seçimi stratejilerinde biyolojik olgunlaşmanın öneminin anlaşılabilmesi, gelişimsel olarak daha uygun bir öğrenme ortamı sunulabilmesi ve özellikle geç olgunlaşan sporcuların psikolojik ve sosyal yönden daha sağlıklı gelişebilmeleri olarak belirtmişlerdir.

\section{SONUÇ ve ÖNERÍLER}

Ülkemizde birçok spor dalında genç sporcular biyolojik olgunluk düzeyinin doğurabileceği bireysel farklıklar gözardı edilerek yalnızca takvim yaşları temel alınarak antrenman ve müsabaka gruplarına ayrılmaktadır. Ancak bu durum birçok yetenekli genç sporcunun erken yaşlarda spordan uzaklaşması riskini doğurabilmektedir. $\mathrm{Bu}$ çalışmada, yeni bir uygulama olmasına karşın popülerliği her geçen gün artan sporda biyo-gruplamaya ilişkin yöntem ve uygulamalar ile birlikte potansiyel yararları konusunda bir çerçeve çizildi. Ayrıca, her ne kadar uygulamanın potansiyel avantaj ve dezavantajları konusunda yeterli bilimsel veri olmasa da; ülkemiz bilim insanları, antrenörleri, spor yöneticileri ve diğer paydaşların konu hakkındaki farkındalıklarının geliştirilmesi amaçlandı.

Biyo-gruplama kronolojik yaş gruplamasının alternatifi olarak değil, tamamlayıcısı olarak algılanmalıdır (1). Genç sporcuların düzenli aralıklarla büyüme ve olgunlaşma düzeyleri değerlendirilmelidir. Bununla birlikte, yılın farklı zamanlarında biyo-gruplama ile organize edilen turnuvalara katılımlarının sağlanması onlara tüm yönleri ile sağlıklı bir gelişim ortamı sunabilir. Sonuç olarak, biyo-gruplama yönteminin daha iyi anlaşılabilmesi için bilim insanları ile uygulamacılar arasında iş birliğinin geliştirilmesi ve daha çok bilimsel araştırmanın yürütülmesine gereksinim vardır. Bu durum ülkemiz spor bilimcileri için yeni bir araştırma konusu olarak düşünülebilir.

Her ne kadar bu çalışmada biyo-gruplamanın olumlu yönleri üzerinde durulmuş olsa da, uygulama aşamasında yöntem bazı riskler barındırabilir. Örneğin, kronolojik olarak üst yaş grubunda yer alan fakat biyolojik olarak geç olgunlaşma düzeyinde bulunan sporcuların alt yaş gruplarında antrenman ve müsabakalara 
katılmaları motivasyonlarını olumsuz yönde etkileyebilir. $\mathrm{Bu}$ nedenle uygulama öncesinde sporcu, antrenör ve velilere yöntemin potansiyel avantaj ve dezavantajları hakkında detaylı bilgi verilmesi yaşanabilecek bu tür problemlerin önüne geçilmesinde önemli rol oynayabilir.

\section{KAYNAKLAR}

1. Cumming SP, Lloyd RS, Oliver JL, et al. Bio-banding in sport: applications to competition, talent identification, and strength and conditioning of youth athletes. Strength Cond J. 2017;39(2):34-47.

2. Johnson, A. Monitoring the immature athlete. Aspetar Sports Med J. 2015;4(1):114-8.

3. Malina RM, Peña Reyes ME, Eisenmann JC, et al. Height, mass and skeletal maturity of elite Portuguese soccer players aged 11-16 years. J Sport Sci. 2000;18(9):685-93.

4. Ryan D, McCall A, Fitzpatrick GF, et al. The influence of maturity status on movement quality among English Premier League academy soccer players. Sport Perf Sci Rep. 2018;32:1-3.

5. Malina RM, Eisenmann JC, Cumming SP, et al. Maturityassociated variation in the growth and functional capacities of youth football (soccer) players 13-15 years. Eur J Appl Physiol. 2004;91(5-6):555-62.

6. Vandendriessche JB, Vaeyens R, Vandorpe B, et al. Biological maturation, morphology, fitness, and motor coordination as part of a selection strategy in the search for international youth soccer players (age 15-16 years). J Sports Sci. 2012;30(15):1695-703.

7. Carvalho HM, Coelho-e-Silva MJ, Eisenmann JC, et al. Aerobic fitness, maturation, and training experience in youth basketball. Int J Sports Physiol Perform. 2013;8(4): 428-34.

8. Torres-Unda J, Zarrazquin I, Gil J, et al. Anthropometric, physiological and maturational characteristics in selected elite and non-elite male adolescent basketball players. J Sport Sci. 2013;31(2):196-203.

9. Myburgh GK, Cumming SP, Silva MC, et al. Maturityassociated variation in functional characteristics of elite youth tennis players. Pediatr Exerc Sci. 2016;28(4): 542-52.

10. Söğüt M, Altunsoy K, Kaya ÖB, et al. Effects of biological maturation on body composition, muscular strength, and agility in female tennis players. Proceedings of the 14th International Scientific Conference of Sport Kinetics. 2018 June 24-27, Poreč, Croatia.

11. Matthys SPJ, Vaeyens R, Coelho-e-Silva MJ, et al. The contribution of growth and maturation in the functional capacity and skill performance of male adolescent handball players. Int J Sports Med. 2012;33(7):543-9.

12. Baker J, Logan AJ. Developmental contexts and sporting success: birth date and birthplace effects in national hockey league draftees 2000-2005. Br J Sports Med. 2007;41(8):515-7.

13. Baxter-Jones AD, Eisenmann JC, Sherar LB. Controlling for maturation in pediatric exercise science. Pediatr Exerc Sci. 2005;17(1):18-30.

14. Lloyd RS, Oliver JL, Faigenbaum AD, et al. Chronological age vs. biological maturation: implications for exercise programming in youth. J Strength Cond Res. 2014;28(5): 1454-64.

15. Malina RM, Rogol AD, Cumming SP, et al. Biological maturation of youth athletes: assessment and implications. Br J Sports Med. 2015;49(13):852-9.

16. Beunen GP, Rogol AD, Malina RM. Indicators of biological maturation and secular changes in biological maturation. Food Nutr Bull. 2006;27(4 Suppl 5: Growth Standard):S244-56.

17. Sherar LB, Mirwald RL, Baxter-Jones AD, et al. Prediction of adult height using maturity-based cumulative height velocity curves. J Pediatr. 2005;147(4):508-14.

18. Mirwald RL, Baxter-Jones AD, Bailey DA, et al. An assessment of maturity from anthropometric measurements. Med Sci Sports Exerc. 2002;34(4):689-94.

19. Beunen GP, Malina RM, Lefevre J, et al. Prediction of adult stature and noninvasive assessment of biological maturation. Med Sci Sports Exerc. 1997;29(2):225-30.

20. Malina RM, Dompier TP, Powell JW, et al. Validation of a noninvasive maturity estimate relative to skeletal age in youth football players. Clin J Sport Med. 2007;17(5): 362-8.

21. Cameron N. Assessment of maturation. In: Cameron N, editor. Human Growth and Development. San Diego: Academic Press; 2002. p. 363-82.

22. Duke PM, Litt IF, Gross RT. Adolescents' self-assessment of sexual maturation. Pediatrics. 1980;66(6),918-20.

23. Rasmussen AR, Wohlfahrt-Veje C, Tefre de Renzy-Martin $\mathrm{K}$, et al. Validity of self-assessment of pubertal maturation. Pediatrics. 2015;135(1):86-93.

24. Baxter-Jones AD, Maffulli N, Mirwald RL. Does elite competition inhibit growth and delay maturation in some gymnasts? Probably not. Pediatr Exerc Sci. 2003; 15(4):373-82.

25. Khamis HJ, Roche AF. Predicting adult stature without using skeletal age: the Khamis-Roche method. Pediatrics. 1994;94(4 Pt 1):504-7.

26. Langan-Evans C, Close GL, Morton JP. Making weight in combat sports. Strength Cond J. 2011;33(6):25-39.

27. Pettersson S, Ekström MP, Berg CM. Practices of weight regulation among elite athletes in combat sports: a matter of mental advantage? J Athl Train. 2013;48(1): 99-108.

28. Cumming SP, Brown DJ, Mitchell S, et al. Premier League academy soccer players' experiences of competing in a tournament bio-banded for biological maturation. J Sport Sci. 2018;36(7):757-65. 